\title{
Indicadores ambientales de áreas verdes urbanas para la gestión en dos ciudades de Costa Rica
}

\author{
Vanessa Morales-Cerdas ${ }^{1 *}$, Lilliana Piedra Castro ${ }^{1}$, Marilyn Romero Vargas ${ }^{2}$ \\ $\&$ Tania Bermúdez Rojas ${ }^{3}$ \\ 1. Laboratorio de Recursos Naturales y Vida Silvestre (LARNAVISI), Escuela de Ciencias Biológicas, Universidad \\ Nacional, 36-3000, Heredia, Costa Rica; vane_moce@hotmail.com, lilliana.piedra.castro@una.cr \\ 2. Escuela de Ciencias Geográficas, Universidad Nacional, 36-3000, Heredia, Costa Rica; \\ marilyn.romero.vargas@una.cr \\ 3. Escuela de Ciencias Biológicas, Universidad Nacional, 36-3000, Heredia, Costa Rica; tania.bermudez.rojas@una.cr
}

$$
\text { Recibido 09-V-2018. C Corregido 26-VII-2018. Aceptado 20-VIII-2018. }
$$

\begin{abstract}
Environmental indicators of urban green areas for management in two cities of Costa Rica. Environmental quality contributes to the physical and mental well-being of the population. In this way, the green areas (GA) of the cities are essential spaces for coexistence, sports, socialization, and recreation, among others. The objective of this research was to determine the environmental conditions of green areas, using indicators as tool for urban management in two cities of Costa Rica. The study area corresponded to the districts of Heredia and Carmen, Costa Rica. The existing GA were determined using Rapid Eye satellite images, 2012 through spatial analysis and remote sensing. Eleven indicators of urban green areas were applied, the species was identified, the height, the diameter at breast height (DBH) and the number of trees in parks and streets were measured. In addition, surveys were conducted to users of public GA, on issues related to accessibility and use of GA. Five types of GA were identified in Carmen and six in Heredia. The percentage of public and private green areas corresponded to $36 \%$ and $64 \%$ in Carmen and $13 \%$ and $87 \%$ in Heredia respectively. The green area per capita $\left(\mathrm{m}^{2} / \mathrm{hab}\right)$ was 24.6 in Carmen and 2.7 in Heredia. Sixty-two species of trees were identified in the Carmen parks and 23 in Heredia. There were 1105 trees of 61 species in the streets, sidewalks and avenues of Carmen and 278 individuals of 47 species in Heredia. Regarding the existence of riparian vegetation, it was determined that Pirro, Burrio, Torres and Negritos streams maintain 82, 51, 81 and $14 \%$ of margin protection areas in conforming use. Eleven of the public GA's were evaluated, nine presented a high physical accessibility. In both districts, the surveyed citizens indicated the necessity to have more GA, highlighting the recreational, ecological and touristic value of these spaces. It is concluded that the indicators of urban green areas showed that there are differences between the environmental conditions in both of the evaluated cities. In addition, the applicability of the indicators is feasible as an input for the sustainable environmental management of urban ecosystems.
\end{abstract}

Key words: environmental indicators; urban green areas; Costa Rica; cities; parks.

Morales-Cerdas, V., Piedra Castro, L., Romero Vargas, M. \& Bermúdez Rojas, T. (2018). Indicadores ambientales de áreas verdes urbanas para la gestión en dos ciudades de Costa Rica. Revista de Biología Tropical, 66(4), 1421-1435.

Las ciudades que buscan enrumbarse hacia la sostenibilidad urbana son aquellas que intentan reducir los recursos externos que utilizan, la generación de residuos y mejorar las condiciones de vida de los habitantes presentes y futuros, en dimensiones clave de la vida cotidiana (salud, ingresos, vivienda, acceso, tiempo libre, espacios públicos y sentido de pertinencia) (Subirats, Quintana, Vidal, \& Rueda, 2012).

Adicionalmente, las áreas verdes (AV) urbanas pueden ser incorporadas como un elemento para la aplicación del concepto de sostenibilidad. La calidad ambiental está condicionada por factores como el acceso al espacio 
público, a la vivienda, a los servicios de salud y educación, al transporte público, al goce de condiciones óptimas de seguridad y a la incidencia directa o indirecta de diversos tipos de contaminación ambiental, que generan una imagen de ciudad percibida y valorada en función del impacto ambiental producido (Pinzón \& Echeverri, 2010). Los conceptos anteriormente descritos se enfocan en mejorar el bienestar humano, concebido como el que cubre las necesidades humanas básicas y se enfoca en valores intangibles que dan sentido a la vida, como las relaciones sociales y los ecosistemas conservados (Aguado et al., 2012).

Es destacable la función que tienen las AV como ecosistemas, ya que inciden de forma positiva en el ambiente, el bienestar humano y la economía urbana (Rente, Krishnamurthy, \& Juhani, 1997). Además, contribuyen con diversos servicios ecosistémicos como la protección de acuíferos, la disminución de la temperatura y la sensación térmica, el control de la escorrentía, la retención de contaminantes atmosféricos y el mejoramiento visual del paisaje (Meza \& Moncada, 2010).

Otras funciones de estas áreas están relacionadas con diversos grupos sociales, desde niños hasta adultos mayores, que las emplean para cubrir necesidades básicas como la convivencia, agrupación, socialización, descanso, recreación y deporte. Además, aportan otros beneficios en la salud física y emocional de la población, al reducir el estrés y contribuir con un ambiente agradable y relajante, que permiten crear una conexión entre la ciudadanía y la naturaleza (Gómez, 2005; Lee \& Maheswaran, 2011).

De modo que su importancia ecológica y social han llevado a que sean utilizadas para valorar las condiciones ambientales y la sostenibilidad en regiones urbanas (Flores, 2012). Debido a lo anterior, la Organización Mundial de la Salud (OMS), el Programa de las Naciones Unidas para el Desarrollo (PNUD) y el Banco Interamericano de Desarrollo (BID), han utilizado indicadores sobre AV para evaluar el desempeño ambiental y comparar entre países.

En el caso de Costa Rica, se ha investigado sobre aspectos relacionados con AV, pero no necesariamente aplicado a indicadores. Incluyen aspectos sobre composición, riqueza y abundancia de especies vegetales en zonas urbanas; manejo y conservación de los árboles en parques, calles o cuencas; importancia de coberturas arbóreas para la recuperación de la biodiversidad, entre otros (Piedra-Castro, Bermúdez-Rojas, \& Romero-Vargas, 2013). Sobre indicadores destaca el aporte del Observatorio Ambiental de la Universidad Nacional y el Observatorio del Desarrollo (OdD) de la Universidad de Costa Rica, que recopilan información en el ámbito ambiental, social y económico (Observatorio Ambiental, 2017; Observatorio del Desarrollo, 2017).

A pesar de la importancia que tiene esta temática en la búsqueda de la sostenibilidad, la investigación en el país es aún incipiente. Panorama que se complica con los múltiples desafíos en la gestión urbana, donde destacan la planificación y el acelerado crecimiento urbano, que genera diversas problemáticas ambientales, como la falta de espacios públicos y AV.

De ahí, que se requiere un conjunto de indicadores que sean metodológica y económicamente viables para evaluar las ciudades. Mismos que permitan generar información y determinar las condiciones ambientales que conlleven a la mejora continua y el bienestar humano. Por lo que el presente estudio tuvo como objetivo determinar las condiciones ambientales de las AV, utilizando indicadores como herramienta para la gestión urbana en dos ciudades de Costa Rica.

\section{MATERIALES Y MÉTODOS}

Área de estudio: El área de estudio se encuentra en el distrito el Carmen, del cantón San José y el distrito Heredia, del cantón Heredia, Costa Rica. El Carmen tiene una extensión aproximada de 147.5 hectáreas (ha), una población de 2702 habitantes, la precipitación media es de 1500 a 2000 milímetros (mm) anuales, la temperatura media anual de 20 a 22 grados centígrados $\left({ }^{\circ} \mathrm{C}\right)$ y la elevación está en el rango de los 1100 a 1200 metros sobre el nivel del mar (msnm). El distrito de Heredia tiene una extensión aproximada de 298.5 ha, 
una población de 19138 habitantes. Presenta una precipitación anual entre 2000 a 3000 $\mathrm{mm}$, la temperatura media anual varía entre los 18 a $20^{\circ} \mathrm{C}$, la elevación está en el rango de los 1100 a 1200 msnm (Ortiz, 2008). En ambos distritos, el suelo tiene una ocupación urbana, se concentran actividades financieras, comerciales, profesionales e institucionales (Municipalidad de Heredia, 2009; Municipalidad de San José, 2012).

\section{Definición e identificación de AV urba-} nas: Se consideró las AV urbanas como aquellos espacios urbanos o de periferia a éstos, ocupados con árboles, arbustos, herbáceas y otras plantas no leñosas, usados para esparcimiento, recreación, conservación, ornamentación, protección, recuperación, rehabilitación del entorno o similares (CONAMA, 2002). Se construyeron las capas de información geoespacial (tipo de AV, condición privada o pública, área, ubicación geográfica) de las AV de cada distrito, utilizando imágenes satelitales Rapid Eye, 2012, suministradas por el Laboratorio PRIAS del Centro Nacional de Alta Tecnología.
La identificación de las AV se realizó mediante clasificación supervisada y fotointerpretación de las imágenes, se hizo la digitalización de los polígonos y el calculó el área $\left(\mathrm{m}^{2}\right)$ de cada $\mathrm{AV}$. Se realizó validación de campo para verificar el uso actual y redefinir los tipos de $\mathrm{AV}$ según las características en sitio (Cuadro 1).

Se aplicaron 11 indicadores ambientales para las AV urbanas, que permitieron la caracterización a nivel de distrito como unidad de paisaje. Dos indicadores para la caracterización general y los restantes para la caracterización socio-ambiental de las AV. Los indicadores generales utilizados se describen a continuación:

Porcentaje de áreas verdes públicas y privadas. Describe el porcentaje de AV públicas y privadas presentes en cada distrito. En este caso las $\mathrm{AV}$ públicas corresponden a zonas de uso público, directo o indirecto, como los parques, los jardines en plazas, árboles en vías públicas, entre otros. Las AV privadas no son accesibles a la ciudadanía por encontrarse dentro de una propiedad privada, por ejemplo,

CUADRO 1

Tipo de áreas verdes presentes en los distritos el Carmen y Heredia

TABLE 1

Type of green areas present in the Carmen and Heredia districts

\begin{tabular}{|c|c|}
\hline Tipo de AV & Descripción \\
\hline Vegetación ribereña & $\begin{array}{l}\text { Coberturas constituidas por vegetación ubicada en las márgenes de los cursos de agua } \\
\text { permanentes o temporales. }\end{array}$ \\
\hline Parque & $\begin{array}{l}\text { Espacios abiertos de uso público, compuestos por especies vegetales, y cuyas condiciones } \\
\text { de ornamentación, topografía y accesibilidad permiten la recreación activa y pasiva de los } \\
\text { ciudadanos. Pueden ser usados para el esparcimiento, recreación, deportes, cultura u otros. }\end{array}$ \\
\hline Pastizal & $\begin{array}{l}\text { Espacios cubiertos con hierbas de composición florística dominada principalmente por } \\
\text { gramíneas o herbáceas. }\end{array}$ \\
\hline Espacio arbolado & $\begin{array}{l}\text { Espacios ocupados por vegetación arbórea, en áreas de bordes de carreteras, en patios } \\
\text { de casa, edificios, industrias, etc. Excluye vegetación arbórea dentro de parque y área de } \\
\text { vegetación ribereña. }\end{array}$ \\
\hline Polideportivo o plaza & $\begin{array}{l}\text { Espacios abiertos compuestos principalmente por áreas de césped. De uso público } \\
\text { destinados al esparcimiento, compuestos por elementos como plaza para futbol, área de } \\
\text { ejercicios y área de juegos. }\end{array}$ \\
\hline Pastizal arbolado & $\begin{array}{l}\text { Espacios cubiertos con hierbas dominada principalmente por gramíneas o herbáceas y } \\
\text { árboles ubicados forma dispersa. }\end{array}$ \\
\hline
\end{tabular}


jardines, pastizales, zonas de protección de ríos y quebradas (Mena, Ormazábal, Morales, Santelices, \& Gajardo, 2011). Se calculó con la siguiente formula:

Tipo de áreas verdes $(\%)=\left(\frac{\operatorname{TAV}\left(\mathrm{m}^{2}\right)}{\operatorname{AV}\left(\mathrm{m}^{2}\right)}\right) * 100$

Donde; $\mathrm{AVpu}$ (área verde pública $\left.\left(\mathrm{m}^{2}\right)\right), \mathrm{AVpr}$ (área verde privada $\left(\mathrm{m}^{2}\right)$ ) y AVt (área total de las zonas verdes $\left.\left(\mathrm{m}^{2}\right)\right)$.

Tipo y tamaño de las áreas verdes: describe los tipos y el tamaño de las AV de cada distrito (Segura \& Trincado, 2003; Cueva \& Chalán, 2010) (Cuadro 1). Para cada tipo de AV se obtuvo el área $\left(\mathrm{m}^{2}\right)$ y el porcentaje ocupado en la zona de estudio. Se calculó a partir de la siguiente fórmula:

Zonas verdes efectivas per cápita $(Z V P H)=\frac{A v}{H}$

Donde; TAV (Tipo de área verde $\left(\mathrm{m}^{2}\right)$ ) y AV (área total de zonas verdes en cada distrito $\left(\mathrm{m}^{2}\right)$ ).

Caracterización social de las AV: Indicadores usados para describir aspectos sociales de las AV públicas. Se aplicaron en los parques Nacional, Morazán, España, Francia y el polideportivo Aranjuez; en Heredia el parque Central, el Carmen, Alfredo Gonzáles y los polideportivos de Fátima, el Carmen y Puebla.

Zonas verdes efectivas per cápita: área de zonas verdes públicas que corresponden a cada habitante, según la totalidad de estas en cada distrito. Se utilizó el número de habitantes residentes según el censo nacional del 2011 (INEC, 2011; Lossio, 2011). Se obtuvo con la siguiente formula:

$$
\text { VRUC } \%=\frac{\mathrm{Vr}}{\mathrm{ZP}} * 100
$$

Donde; Av (área total de las zonas verdes públicas, $\mathrm{m}^{2}$ ) y $\mathrm{H}$ (número de habitantes).

Cercanía de los poblados a las áreas verdes de uso público mayores a $5000 \mathrm{~m}^{2}$ : se identificó la cercanía de las $\mathrm{AV}\left(\geq 5000 \mathrm{~m}^{2}\right)$ a los barrios de cada distrito. A partir del centro de cada AV (Parque, Nacional, Morazán y Central) se midió la distancia lineal hasta el centro de cada barrio. Según está distancia se categorizó la cercanía de la siguiente forma: entre 0 a $300 \mathrm{~m}$ alta, de 301 a $600 \mathrm{~m}$ media, más de 601 m baja (Gómez, 2013) y se calculó el porcentaje de poblados dentro de cada categoría.

Accesibilidad física en las áreas verdes de uso público: hace referencia al grado de accesibilidad que presentaban las AV de uso público, según las condiciones de infraestructura y requerimientos básicos para la ciudadanía. Se realizó la sumatoria total para cada AV tras la valoración de los siguientes aspectos: la presencia (Equivale a 2) o ausencia (Equivale a 0) de área de juegos, basureros, bancas, alumbrado, rampas de acceso, cruces peatonales, semáforos, ancho adecuado de las aceras ( $>1.2$ $\mathrm{m})$, baños públicos, parqueo y superficies resbaladizas (*Excepción: la presencia equivale a -2). Además del estado de las aceras (bueno = 3 , regular $=2$, malo $=1$, , porcentaje del AV con espacios con sombra $(>50 \%=3 ; 50 \%$ a 25 $\%=2 ;<25 \%=1$ ) y la cercanía a los sitios de residencia $(<300 \mathrm{~m}=3$; 300 a $900 \mathrm{~m}=2$; > $900 \mathrm{~m}=1)$. Se clasificó de la siguiente forma: alta entre 27 a 39 puntos; mediana de 14 a 26 y baja de 0 a 13 (Martínez, 2011; Alfaro, 2016).

Uso social de las áreas verdes públicas: identificó la utilidad dada por la población a las AV públicas. Se aplicaron 35 encuestas en cada AV pública de ambos distritos, para un total de 210 en Heredia y 175 en el Carmen. Se consultó el género, edad, lugar de residencia, con quien se visita el AV, hora en que la visita, tiempo de permanencia, frecuencia de visita, distancia del sitio de residencia al AV, actividades realizadas, actividades recreativas de preferencia, aspectos a mejorar en estos sitios. Se obtuvieron porcentajes según frecuencias de uso, grupo etario, acompañamiento, horario de vista, cantidad de visitas semanales, tiempo de permanencia, entre otros (Arribas, 2004; Romano, 2005).

Caracterización ambiental de las AV: Indicadores utilizados para describir aspectos ambientales de las AV. Para los correspondientes a aplicar en parques se usaron 
los siguientes sitios: parque Nacional, Morazán, España, Francia, Central, el Carmen y Alfredo Gonzales.

Vegetación ribereña según uso conforme a la Ley Forestal (\%): porcentaje del área en donde se cumplió con la zona de protección de $10 \mathrm{~m}$ en ambos lados del cauce, correspondiente para zonas urbanas según la Ley Forestal (Nº7575) de Costa Rica (La Gaceta, 1996). Se identificaron los ríos y quebradas en las zonas de estudio (Ortiz, 2008). Se determinó el área de protección ribereña estableciendo una zona de amortiguamiento de $10 \mathrm{~m}$ en los márgenes de cada cuerpo de agua. Se estimó el área correspondiente a la zona de protección (ZP) y se calculó el área ocupada por vegetación ribereña $(\mathrm{Vr})$ dentro de esta. Se estimó con la siguiente formula:

$$
\mathrm{IBS}=\left[\sum(\mathrm{fi} \mathrm{x} \text { ai) } / \mathrm{At}]\right.
$$

Donde; $\operatorname{Vr}$ (área cubierta por vegetación ribereña), ZP (área de la zona de protección).

Composición, abundancia y estructura de especies arbóreas en parques urbanos: describió las especies arbóreas presentes en parques, así como la composición y abundancia. Se realizó un censo y se identificaron las especies de árboles mayores a $1.5 \mathrm{~m}$ de altura, se calculó el porcentaje de especies nativas y exóticas, se midió el diámetro a la altura del pecho (DAP) y la altura $(\mathrm{m})$. Se determinó la abundancia por distrito empleando el índice de Shannon Weber y la equitatividad con el índice de BergerParker (Amaya et al., 2008).
Arbolado en calles, aceras y avenidas: se registró el número relativo de árboles plantados en calles, avenidas y aceras. Se realizó un censo de las especies de árboles $(\geq 1.5 \mathrm{~m}$ de altura) presentes en estos sitios, se obtuvo el porcentaje de especies nativas y exóticas, el número de árboles y especies promedio por calles, aceras y avenidas en cada distrito (Escobar, 2009).

Permeabilidad del suelo en parques urbanos: mostró una relación entre las superficies funcionalmente significativas en el ciclo natural del suelo y la superficie de cada parque. Se realizó la identificación de los tipos de superficies y el área ocupada por cada una. Se establecieron las descripciones y puntuaciones para los tipos de superficies presentes en los parques en función de su naturalidad (Agencia de Ecología Urbana de Barcelona, 2010) (Cuadro 2). A partir de estas se calculó del índice biótico del suelo (IBS), con la siguiente formula:

$$
\begin{gathered}
\mathrm{IF}=\mathrm{A}^{0.15}+\mathrm{B}^{0.12}+\mathrm{C}^{0.12}+\mathrm{D}^{0.05}+\mathrm{E}^{0.06} \\
+\mathrm{F}^{0.05}+\mathrm{G}^{0.05}+\mathrm{H}^{0.05}+\mathrm{I}^{0.02}-\mathrm{J}^{0.1}-\mathrm{K}^{0.05}
\end{gathered}
$$

Donde; fi (factor de tipo de sustrato), ai (área del tipo de superficie) y At (área total del parque).

Índice de funcionalidad para la avifauna de los parques urbanos: se evaluó el potencial de los parques urbanos $\left(\geq 5000 \mathrm{~m}^{2}\right)$ para alojar la máxima diversidad de avifauna. Se utilizó considerando que la diversidad de este grupo trófico superior muestra implícitamente la diversidad de grupos inferiores, valora las condiciones óptimas de cobertura vegetal, especies

\section{CUADRO 2}

Tipos de superficies presentes en los parques del Carmen y Heredia

TABLE 2

Types of surfaces present in the parks of Carmen and Heredia

\begin{tabular}{ll}
$\begin{array}{c}\text { Tipo de superficie } \\
\text { (factor de tipo de superficie) }\end{array}$ & \multicolumn{1}{c}{ Descripción } \\
Impermeables $(0)$ & $\begin{array}{l}\text { Zonas con pavimento impermeabilizado respecto a la difusión agua y al aire, sin } \\
\text { funciones ecológicas. Por ejemplo, el asfalto, los adoquines, el cemento. }\end{array}$ \\
Impermeabilizadas parcialmente $(0,3)$ & $\begin{array}{l}\text { Superficies que permiten el traspaso de aire y agua, se da infiltración, pero el } \\
\text { suelo no es visible y no presenta ninguna plantación. Por ejemplo, piedra de } \\
\text { grava, piedra volcánica o arena. }\end{array}$ \\
Permeables (1) & $\begin{array}{l}\text { Espacios verdes con conexión con suelo natural, presentan estructura } \\
\text { edafológica, se desarrollan flora y fauna. }\end{array}$ \\
\hline
\end{tabular}


vegetales, fuentes de agua, sitios para descanso o refugio, entre otros, para albergar este grupo en particular y permite valorar el efecto de las características de diseño y gestión de las AV en la riqueza de especies de aves. Este índice fue calculado apegándose a la fórmula establecida por la Agencia de Ecología de Barcelona (2010), según se describe a continuación

Donde A: área del parque (ha), B: cobertura arbórea (\%), C: arbustos (\%), D: césped $(\%)$, E: agua (\%), J: superficie artificial (\%), F: número de árboles de porte grande (diámetro de copa $\geq 6 \mathrm{~m}$ y altura $>15 \mathrm{~m}$ ), G: número de árboles de porte medio (diámetro de copa entre 4 y $6 \mathrm{~m}$ y altura $\leq 15 \mathrm{~m}$ ), H: número de árboles de porte pequeño (diámetro de copa $<$ $4 \mathrm{~m}$ y altura $<6 \mathrm{~m}$ ), I: diversidad de especies de árboles (índice de Shannon-Weaber $(\mathrm{H}=$ $\left.\left.\Sigma \mathrm{p}_{\mathrm{i}}{ }^{*} \log _{2} \mathrm{p}_{\mathrm{i}}\right)\right), \mathrm{K}$ : distancia al hábitat fuente más cercano que corresponde a la distancia lineal en $\mathrm{km}$ desde el sitio en estudio hasta el Área Silvestre Protegida más cercana.

Análisis de datos: Para los análisis espaciales y de teledetección, el cálculo del área $\left(\mathrm{m}^{2}\right)$ de los polígonos de las AV y la elaboración de mapas temáticos se utilizaron los programas ENVI 5.1, ArcGis 10.3 y Quantum Gis. Los índices de Shannon, Berger-Parker y diversidad de especies $(\mathrm{H})$ se calcularon con el programa Biodiversity professional 2.

\section{RESULTADOS}

Caracterización general de las AV urbanas: En el Carmen, las AV representan el $12 \%$ del territorio y en Heredia ocupan el $10.5 \%$. El Carmen tiene 17.7 ha de AV, de las cuales 6.3 ha corresponden a zonas de uso público, que equivale a $37 \%$ y el $63 \%$ restantes son
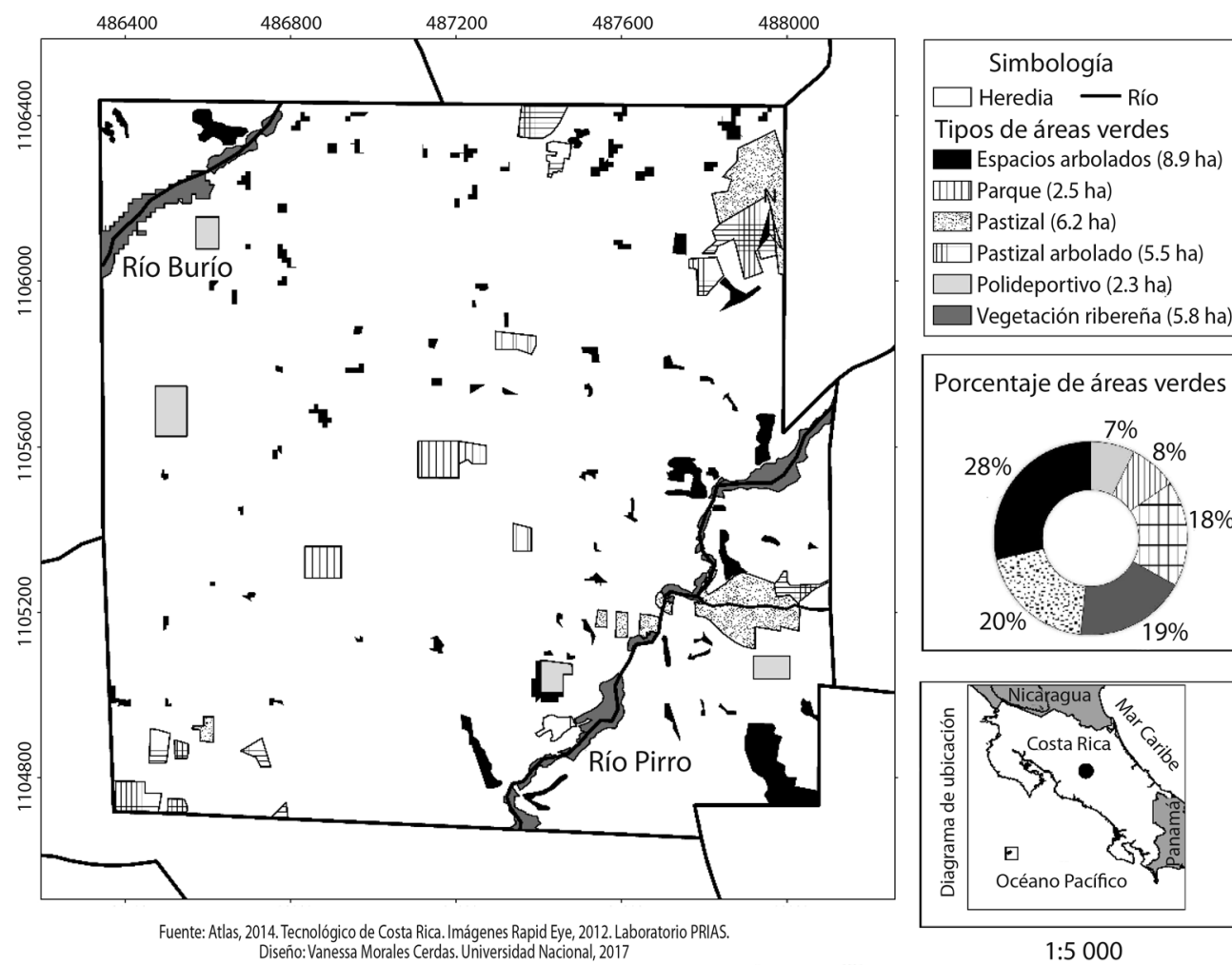

Porcentaje de áreas verdes
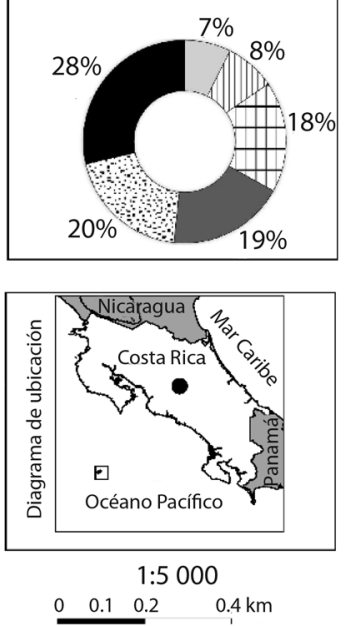

Fig. 1. Tipo y tamaño de áreas verdes en el distrito de Heredia, Heredia, 2016.

Fig. 1. Type and size of green areas in the district of Heredia, Heredia, 2016. 
AV privadas. Heredia abarca un total de 31.32 ha, de las cuales 4.1 ha son a AV públicas, lo que representa $13 \%$ y el restante $87 \%$ son AV privadas.

Estas AV correspondieron a seis tipos, estos fueron: espacios arbolados, vegetación ribereña, parques, pastizales, polideportivos o plaza y pastizales arbolados (Cuadro 1). En Heredia están presentes estos seis, siendo los espacios arbolados los que tuvieron el mayor porcentaje con $28 \%$ (Fig. 1). En el Carmen se identificaron cinco y fue la vegetación ribereña la que ocupó el mayor porcentaje (47\%) (Fig. 2).

Caracterización social de las AV: En el Carmen se identificaron $24.6 \mathrm{~m}^{2}$ de área verde per cápita $\left(\mathrm{m}^{2} / \mathrm{hab}\right)$, mientras en Heredia $2.7 \mathrm{~m}^{2} / \mathrm{hab}$. El Carmen tiene poca población residente y alta población flotante, por lo que es necesario incluir a la población flotante dentro de este indicador para que reflejen la realidad. La Organización Mundial de la Salud recomienda un valor mínimo de $9 \mathrm{~m}^{2} / \mathrm{hab}$ (Reyes \& Figueroa, 2010), pero en Heredia se identificaron $2.7 \mathrm{~m}^{2} / \mathrm{hab}$, esto implica que aproximadamente falten 12 ha de AV para acercarse a dicho valor.

En cuanto a la cercanía de los poblados a las AV públicas mayores a $5000 \mathrm{~m}^{2}$, en el distrito del Carmen, el $28.5 \%$ de los barrios presentaron cercanía alta, $43 \%$ media y $28.5 \%$ baja. El Barrio el Carmen es el que se encuentra a menor distancia de una de estas AV (145 m) y el Barrio el Empalme a mayor distancia (765 m). En Heredia, $11 \%$ de los barrios tienen cercanía alta a un AV, $50 \%$ media y $39 \%$ baja, siendo Barrio los Ángeles el que se encuentra a menor distancia (75 m) y Barrio la Puebla a mayor (920 m).
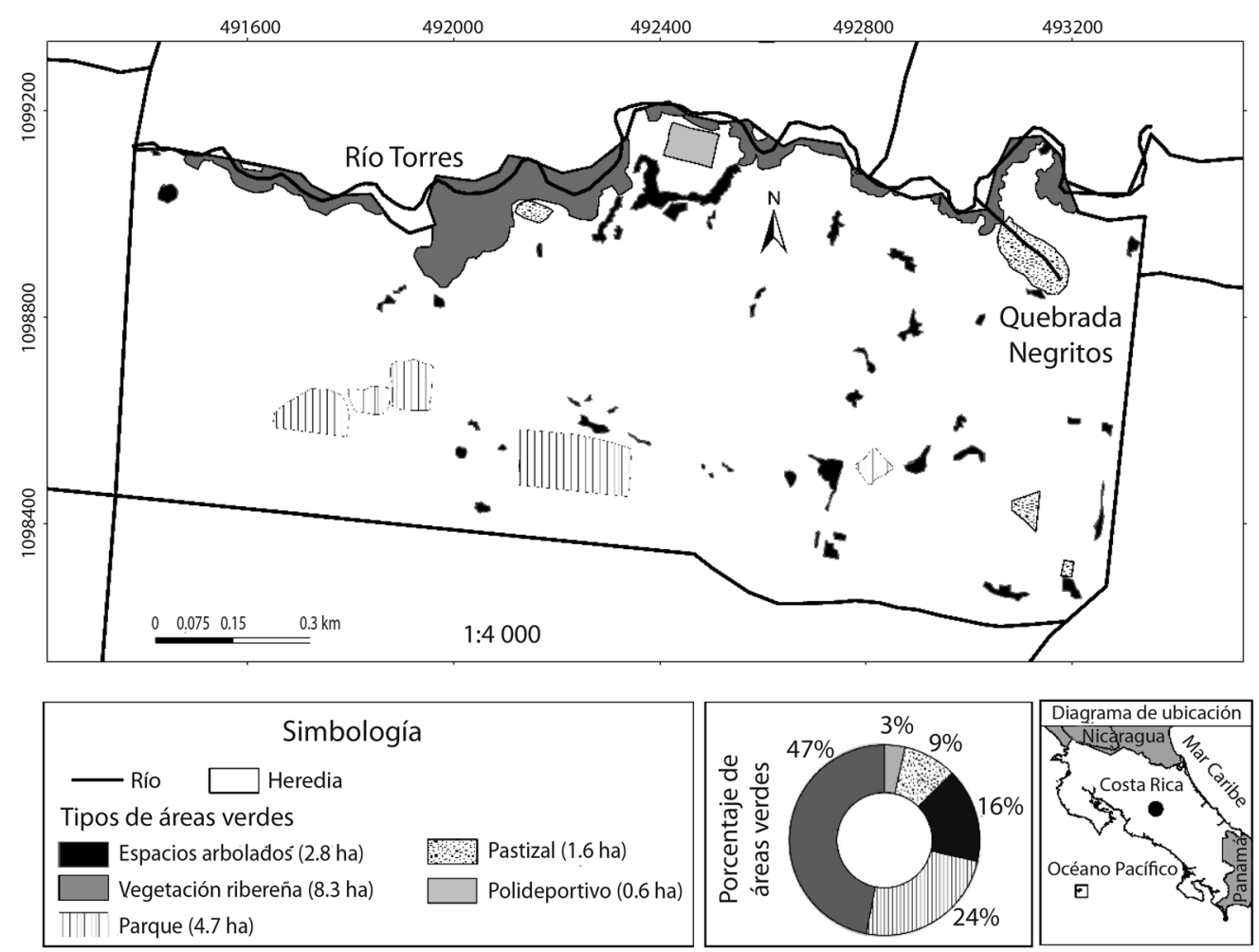

Fuente: Atlas, 2014. Tecnológico de Costa Rica. Imágenes Rapid Eye, 2012. Laboratorio PRIAS. Diseño: Vanessa Morales Cerdas. Universidad Nacional, 2017

Fig. 2. Tipo y tamaño de áreas verdes en el distrito del Carmen, San José, 2016.

Fig. 2. Type and size of green areas in the Carmen district, San José, 2016. 
La accesibilidad física a las AV públicas de ambos distritos es media. Por ejemplo, en Heredia, los parques Central, Carmen, Alfredo Gonzales y los polideportivos Fátima y La Puebla presentaron accesibilidad media (21, 20, 19, 19 y 17 respectivamente); excepto el polideportivo del Carmen que presentó accesibilidad baja (11 puntos).

En el Carmen, los parques Nacional, Morazán, Francia y el polideportivo de Aranjuez presentaron accesibilidad media, con valores de 26, 26, 23 y 22 respectivamente. Únicamente, el parque España obtuvo accesibilidad alta. Las AV del Carmen obtuvieron mayores puntuaciones respecto a las de Heredia.

En este sentido se destacan los siguientes aspectos: los alrededores de estas AV carecen de cruces peatonales debidamente marcados y semáforos, la seguridad es buena o media y no presentan características favorables para adultos mayores y niños. Por ejemplo, las rampas de acceso, fuentes de agua potable, servicios sanitarios, áreas de juegos y los espacios con sombra son escasos.

Aunque las AV no cumplen con todos los aspectos estructurales que la ciudadanía desearía, son espacios de gran importancia, de manera que en ambos distritos más del $80 \%$ de los encuestados indicaron hacer uso de estos. Cabe resaltar que $54 \%$ de los entrevistados fueron hombres y el restante mujeres. Las AV que presentaron el mayor porcentaje de visitación fueron el parque Morazán (30 \%) y Central
(33\%) en el Carmen y Heredia, esto porque al ser parques de gran tamaño son utilizados por las municipalidades y diversas organizaciones para hacer conciertos, exposiciones de artes, ferias, entre otros.

Así mismo, por encima del $65 \%$ de los entrevistados, en ambos distritos, señalaron que es necesario más AV en sus ciudades, otorgándoles un valor recreativo, ecológico, turístico, deportivo o asociado a la salud. En ambos sitios, se identificaron preferencia en cuanto a los horarios y frecuencia de visita, acompañamiento, entre otros (Cuadro 3).

Caracterización ambiental de las AV: La tendencia en las áreas de protección de ríos y quebradas del país es hacia la disminución como resultado del desarrollo urbano. En el caso del Carmen, se identificaron el río Torres y la quebrada Negritos, con longitudes del cauce de 2760 m y 229 m respectivamente. En el río Torres, la zona de protección corresponde a $55411 \mathrm{~m}^{2}$, de los cuales $44900 \mathrm{~m}^{2}$ presentan vegetación ribereña, representando $81 \%$ de la zona en uso conforme. Mientras que el área de protección de la Quebrada Negritos es de $4895 \mathrm{~m}^{2}$, con solo $687 \mathrm{~m}^{2}$ en uso conforme que representa un $14 \%$.

En el caso de Heredia, se identificaron dos ríos, el Pirro y el Burío. Los cuales presentan longitudes del cauce de $1780 \mathrm{~m}$ y $600 \mathrm{~m}$ respectivamente. El área de protección del río Pirro es de $38164 \mathrm{~m}^{2}$, de los cuales $19538 \mathrm{~m}^{2}$

CUADRO 3

Uso social de las áreas verdes públicas en el Carmen y Heredia, 2016

TABLE 3

Social use of public green areas in Carmen and Heredia, 2016

\begin{tabular}{lllll}
\multicolumn{1}{c}{ Aspecto } & \multicolumn{5}{c}{ Porcentaje más representativo (\%) } \\
\cline { 2 - 5 } \multicolumn{1}{c}{ Carmen } & \multicolumn{3}{c}{ Heredia } \\
Horario de visita & Mañana & 34 & Mañana & 44 \\
Acompañamiento & Amigos & 39 & Niños & 30 \\
Tiempo de permanencia & Más 2 horas & 34 & 2 horas & 38 \\
Frecuencia de visita & Ocasional & 31 & 1 x semana & 33 \\
Actividades realizadas & Descansar-conversar & 43 & Deporte-ejercicio & 33 \\
Aspectos a mejorar & Limpieza-seguridad & 46 & Infraestructura & 48 \\
\hline
\end{tabular}


presentó uso conforme y equivale a $51 \%$. Mientras que la zona de protección del río Burío corresponde a $12281 \mathrm{~m}^{2}$, de los cuales $10065 \mathrm{~m}^{2}$ está en uso conforme, es decir $82 \%$ del cauce.

En relación con el arbolado en calles, aceras y avenidas, en el Carmen se contabilizaron 1105 árboles, de 61 especies, en un total de 38 calles y avenidas, con un promedio de 29 árboles y 1.6 especies por calle y avenida. El $32 \%$ de las especies fueron nativas. Las especies que presentaron mayor abundancia fueron Malpighia glabra, Callistemon citrinus, Tabebuia rosea, Trichilia havanensis y Ligustrum lucidum. En Heredia, se contabilizaron 278 árboles, de 41 especies, en un total de 35 calles y avenidas. En promedio, se encontraron 8 árboles y 1.3 especies por calle y avenida. El $41 \%$ de las especies fueron nativas. Tabebuia rosea, Cojoba arbórea, Terminalia catappa, $C$. citrinus y Ficus benjamina fueron las especies más abundantes.

La composición, abundancia y estructura de especies arbóreas en parques urbanos mostro, en el Carmen, 470 árboles de 62 especies (27 familias y 50 géneros) y en Heredia, 101 árboles de 23 especies (12 familias y 21 géneros). En ambos sitios, el mayor porcentaje fueron especies nativas. Los parques del Carmen presentaron mayor diversidad y dominancia de especies (Cuadro 4).

Aunque, la presencia de numerosos individuos y especies de árboles representa un aspecto positivo a resaltar, destaca la deficiencia de áreas permeables en estos parques. En el 14 $\%$ de los sitios evaluados, el área permeable es inferior al $50 \%$. En el Carmen, los parques Nacional, Francia, España y Morazán presentaron $43,41,27$ y $23.4 \%$ respectivamente para el IBS. En Heredia, los parques Carmen, Alfredo Gonzales y Central registraron los siguientes valores 68,48 y $32 \%$ respectivamente.

Según el índice de funcionalidad para la avifauna de los parques urbanos, el parque que presentó mayor puntaje fue el Nacional. Sin embargo, ninguno alcanzo el valor deseable de 7.5 que establece la Agencia de Ecología urbana de Barcelona (2010) como adecuado para

CUADRO 4

Composición, abundancia y estructura de especies arbóreas en parques urbanos del Carmen y Heredia

TABLE 4

Composition, abundance and structure of tree species in urban parks of Carmen and Heredia

\begin{tabular}{|c|c|c|}
\hline \multirow{2}{*}{ Aspecto } & \multicolumn{2}{|c|}{ Distrito } \\
\hline & El Carmen & Heredia \\
\hline Abundancia relativa & 1.42 & 1.14 \\
\hline Dominancia & 0.21 & 0.19 \\
\hline Especies nativas (\%) & 54 & 61 \\
\hline Especies de mayor abundancia & $\begin{array}{l}\text { Citharexylum donnell-smithii (Greenm.) } \\
\text { Melaleuca quinquenervia (Blake.) } \\
\text { Spathodea campanulata (Beauv.) } \\
\text { Jacaranda mimosifolia (Don.) } \\
\text { Cupressus lusitánica (Mill.) } \\
\text { Mangifera indica (L.) } \\
\text { Fraxinus uhdei (Wenz.) }\end{array}$ & $\begin{array}{l}\text { Tabebuia rosea (Bertol.) } \\
\text { S. campanulata (Beauv.) } \\
\text { J. mimosifolia (Don.) } \\
\text { Murraya paniculata (Jack.) } \\
\text { Bauhinia variegata (L.) } \\
\text { C. donnell-smithii (Greenm.) } \\
\text { Trichilia havanensis (Browne.) }\end{array}$ \\
\hline $\mathrm{DAP}(\mathrm{cm})$ & $\begin{array}{l}\text { Mínimo: } 4.4 \\
\text { Máximo: } 273.3 \\
\text { Promedio: } 44 \\
\text { Rango predominante } 1 \text { a } 20 \mathrm{~cm}\end{array}$ & $\begin{array}{l}\text { Mínimo: } 5 \\
\text { Máximo: } 256.2 \\
\text { Promedio: } 42 \\
\text { Rango predominante } 21 \text { a } 40 \mathrm{~cm}\end{array}$ \\
\hline Altura (m) & $\begin{array}{l}\text { Mínimo: } 2 \\
\text { Máximo: } 30 \\
\text { Promedio: } 9 \\
\text { Rango predominante } 4 \text { a } 7\end{array}$ & $\begin{array}{l}\text { Mínimo: } 5 \\
\text { Máximo: } 16 \\
\text { Promedio: } 5.6 \\
\text { Rango predominante: } 4 \text { a7 }\end{array}$ \\
\hline
\end{tabular}


este indicador. En el caso del parque Central, el área protegida considerada como hábitat fuente fue el Parque Nacional Braulio Carrillo-Sector Volcán Barva, mientras para el parque Nacional fue la Zona Protectora Cerros de la Carpintera (Cuadro 5).

\section{DISCUSIÓN}

Los servicios ecosistémicos de las AV dependen de las formaciones vegetales presentes. En el caso de los espacios y pastizales arbolados (comunes en ambos distritos) permiten la filtración del aire, ofrecen fuentes de alimento, sitios de paso o de refugio para aves y otros grupos taxonómicos. Así mismo, la vegetación ribereña regula la temperatura, proporciona hábitat para especies de flora y fauna, permite la conectividad y desplazamiento de fauna, aspecto relevante considerando que los hábitats en zonas urbanas son cada vez menos y el grado de fragmentación es alto. También, las AV contribuyen con la captura de carbono a nivel global y ofrecen servicios de apoyo, tales como la formación de suelo, la polinización y el flujo de nutrientes (McDonald, 2009; Breuste, Qureshi, \& Li, 2013).

En este sentido, no solo la composición vegetal tiene implicaciones a nivel ambiental o social. Aspectos como el tamaño pueden potencializar los beneficios que percibimos de las AV. De tal modo que las de mayor tamaño favorecen la diversidad y riqueza de especies, contribuyen de forma efectiva en la regulación de las inundaciones al mantener la permeabilidad del suelo y la capacidad de infiltración (Reyes \& Figueroa, 2010). Mientras que desde el punto de vista social, favorecen el desarrollo de diversas actividades y facilitan la presencia simultánea de distintos grupos etarios como niños, adultos y jóvenes (Sugiyama \& WardThompson, 2008).

En ambos distritos, el mayor porcentaje de AV fueron privadas, a pesar de no poder ser utilizadas por la ciudadanía, son sitios de importancia, que contribuyen a mejorar la calidad ambiental y el bienestar humano. Debido a que generan a nivel local servicios ecosistémicos, por ejemplo mejoras en la calidad del aire y la disminución de niveles de ruido, aspectos que no se pueden mejorar con la ayuda de los ecosistemas distantes (Bolund \& Hunhammar, 1999; Meza \& Moncada, 2010; Breuste, Schnellinger, Qureshi, \& Faggi, 2013).

En los valores de AV per cápita, en los distritos, se evidenció contraste entre la gestión ambiental realizada. Por un lado, el déficit en Heredia podría estar vinculado con la falta de

CUADRO 5

Funcionalidad ecológica de parques urbanos en el Carmen y Heredia

TABLE 5

Ecological functionality of urban parks in El Carmen and Heredia

\begin{tabular}{|c|c|c|c|c|}
\hline \multirow{2}{*}{ IFP } & \multirow{2}{*}{ Sitio } & Parque Central & Parque Morazán & Parque Nacional \\
\hline & & 5.74 & 6.81 & 7.25 \\
\hline \multirow{11}{*}{ 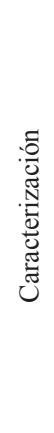 } & Superficie (ha) & 0.8729 & 1.1589 & 2.2887 \\
\hline & Distancia al hábitat fuente más cercano $(\mathrm{km})$ & 11 & 6.5 & 6.5 \\
\hline & \% Árboles & 19 & 41 & 48 \\
\hline & $\%$ Arbustos & 2 & 2 & 2.5 \\
\hline & \% Césped & 26 & 26 & 43 \\
\hline & $\%$ Agua & 1 & 0 & 0 \\
\hline & $\%$ Artificial & 74 & 74 & 57 \\
\hline & Diversidad (H) & 1.02 & 1.51 & 1.53 \\
\hline & $\mathrm{N}^{\circ}$ árboles pequeños & 29 & 44 & 105 \\
\hline & $\mathrm{N}^{\mathrm{o}}$ árboles medianos & 20 & 63 & 126 \\
\hline & $\mathrm{N}^{\circ}$ árboles grandes & 0 & 0 & 24 \\
\hline
\end{tabular}


planificación urbana y la no priorización de la necesidad de más espacios verdes públicos en la ciudad. Mientras que en el Carmen, la gestión ha estado orientada a conservar y mejorar las áreas verdes existentes e incentivar a los ciudadanos para que se apropien de estos espacios.

También, destaca que estas ciudades carecen de AV de gran tamaño y la cercanía con los barrios no se aproxima a lo sugerido por autores como Handley et al. (2003). Quienes indican que los barrios no deben ubicarse a una distancia superior a $300 \mathrm{~m}$ de un AV de al menos 2 ha. Mientras que Reyes y Figueroa (2010), sugieren que para ciudades latinoamericanas, que las $\mathrm{AV}$ sean mayores o iguales a media hectárea $\left(5000 \mathrm{~m}^{2}\right)$. Asimismo, Barbosa et al. (2007) proponen que los barrios no se ubiquen a una distancia máxima de $900 \mathrm{~m}$.

En los distritos analizados, el mayor porcentaje de barrios no cumple con lo sugerido por los citados autores, se consideró que no son aplicables en estos. Debido que las AV de ese tamaño son escasas y se concentran en un sector del distrito. Por ejemplo, en el sector central, Heredia y el Carmen hacia el suroeste, donde se ubican las áreas de servicios y no las habitacionales, lo que propicia que un bajo porcentaje de la población habite a menos de 300 $m$ de un AV de este tamaño.

En cuanto al uso de las AV públicas se encontraron semejanzas en ambos distritos. Las personas prefieren visitarlas durante la mañana y permanecen dos o más horas para descansar y/o conversar. Los parques más utilizados coinciden con los que presentaron el mayor grado de accesibilidad, así mismo la seguridad y el estado de las AV. Teniendo en cuenta que la calidad del AV se determina por el valor que le da el usuario a la experiencia de visitarla y puede influir en la decisión de hacer uso de esta. De igual modo, la sensación de seguridad, encontrar el AV limpia y con señales de un buen mantenimiento influye positivamente (González, 2009).

También, estas AV permiten a la población cubrir una variedad de necesidades individuales o grupales. Sin embargo, es necesario que se cuente con opciones variadas para solventar los requerimientos de los diversos grupos etarios. Por ejemplo, áreas de juegos, de ejercicio, sitios para hacer deporte, espacios con árboles, césped, sitios de descanso, entre otros elemento que hagan que los usuarios se sientan a gusto y pueden realizar diversas actividades.

Ahora bien, respecto a las condiciones ambientales de las AV, se obtuvo en el caso del indicador de vegetación ribereña según el uso conforme a la Ley Forestal, que los ríos Torres y Burío, presentaron un valor favorable. En el río Torres se destaca la presencia del proyecto Corredor Biológico Interurbano río Torres (Artavia \& Valle, 2013), el cual ha representado un aspecto positivo en el mantenimiento de la cobertura vegetal del cauce. Esto favorece la conectividad y a la vez, facilita el desarrollo de iniciativas de conservación (Harvey, Guindon, Haber, Hamilton, \& Murray, 2007).

También, se observaron aspectos negativos, por ejemplo, en el río Pirro se presentan procesos de fragmentación a lo largo del cauce, es común encontrar espacios desprovistos de vegetación e infraestructuras dentro de la zona de protección. Lo cual evidencia el limitado cumplimiento de la Ley Forestal $\left(\mathrm{N}^{\circ}\right.$ 7575) y la limitada actuación de las municipalidades y el Ministerio de Ambiente y Energía, así como la escasa gestión socio-ambiental de estas zonas. Esto causa problemas ecológicos y sociales, tales como el aumento de procesos erosivos, derrumbes, inundaciones y contaminación, que conllevan pérdidas económicas, afectaciones en la salud humana y en los ecosistemas.

Con respecto al arbolado en parques, un aspecto a resaltar es que el mayor porcentaje de especies fueron nativas. Por lo que se debe considerar que el mantenimiento y la reforestación de estas áreas, puede contribuir con la conservación de la biodiversidad. Además, con el manejo adecuado, estos espacios pueden funcionar como reservorios de numerosas especies nativas (Gurrutxaga \& Lozano, 2007). A su vez, los árboles y los espacios verdes generan diversos beneficios, por ejemplo, contribuyen a mantener frescas las ciudades, actúan como filtros naturales en la absorción del ruido y el 
$\mathrm{CO}_{2}$, protegen y elevan la calidad de los recursos naturales como el suelo, agua, vegetación y fauna, son un atractivo estético y mejoran la salud de los habitantes (Jiménez, 2013).

Así mismo, los árboles plantados en calles, aceras y avenidas son elementos importantes en la regulación de la temperatura urbana, debido a que tienen la capacidad de capturar partículas y renovar el aire, así como favorecer las condiciones micro-climáticas al disminuir la sensación térmica (Hernández, 2009). En este sentido, la cantidad de árboles plantados en parques, calles y avenidas del Carmen fue mayor que en Heredia, por lo que el arbolado del Carmen puede presentar mayor potencial para la captura del carbono, en la regulación de la temperatura y la producción de oxígeno.

Según Sánchez y Artavia (2013), es recomendable que alrededor de $75 \%$ a $80 \%$ de especies usadas en la arborización sean nativas. Debido a que las especies nativas se encuentran bien adaptadas al clima local, ayudan a la preservación de la vida silvestre nativa, especialmente aves y pequeños mamíferos como los murciélagos y las ardillas. En este sentido, el porcentaje de especies nativas en calles, aceras $\mathrm{y}$ avenidas fue bajo, lo cual puede deberse a que los gestores urbanos estén dando prioridad a características como la resistencia a la contaminación, al pequeño o mediano porte, al crecimiento rápido, a las floraciones y los follajes atractivos, las cuales son características destacables en las especies exóticas (VargasGarzón \& Molina-Prieto, 2010).

Otro aspecto importante a considerar en las ciudades es que la impermeabilización y compactación del suelo ha limitado la infiltración, aumentando la escorrentía y los riesgos de erosión e inundación. Por lo que las zonas que presentan suelos expuestos adquieren importancia, tal es el caso de las AV y jardines domésticos, de modo que es recomendable implementar patrones de edificación de bajo impacto en parques, en donde las superficies no permeables se ajusten a las necesidades reales de uso público, para que sean espacio en los que se incremente las superficies permeables (Fernández \& González, 2008; Argañaraz \& Lorenz, 2010). Esta condición no se observó en las AV analizadas, que mostraron tendencias de diseño enfocados en la permeabilización del mayor porcentaje de estos espacios. En Heredia, los diseños son cada vez más restrictivos, siendo que el porcentaje de espacio que puede ser usado por la ciudadanía es bajo debido a que las áreas de césped están cerradas al público.

La presencia de vegetación, tanto en calles como parques, y la existencia de zonas permeables, no solo contribuyen a que se cuente con espacios saludables para la ciudadanía sino que generan mayor número de servicios ecosistémicos, con los cuales se favorecen las personas y los diversos grupos faunísticos. Dentro de estos, las aves que fue utilizado como grupo base para valorar la funcionalidad ecológica de estos y para identificar qué características pueden ser favorables y potencializar funciones ecológicas.

En este sentido, los resultados obtenidos con la aplicación del índice de funcionalidad para la avifauna de parques urbanos, permitió identificar que los menores puntajes se deben a que son $\mathrm{AV}$ pequeñas, tiene pocos árboles, carecen de árboles superiores a los $15 \mathrm{~m}$ de altura, las fuentes de agua son pocas y tiene un bajo porcentaje de áreas con arbustos y césped. Características que según Cerdas (2014) son de importancia para la avifauna ya que utilizan principalmente árboles con alturas de $20 \mathrm{~m}$ a $30 \mathrm{~m}$, que sobresalen en el paisaje urbano. Además, la cobertura foliar, la altura máxima y la diversidad de estratos arbóreos son indicadores de riqueza de especies y composición trófica de las aves (MacGregor-Fors, 2008). Se evidencia que las AV analizadas carecen de aspectos básicos para ser ecológicamente funcionales para las aves y que con las características actuales favorecen a las especies generalistas y exóticas como la paloma de castilla (Columba livia) catalogada como especie plaga en zonas urbanas.

Una ventaja de los indicadores aplicados fue el establecimiento de una línea base sobre el estado de las AV, necesaria para la toma de decisiones informadas y la definición de líneas de acción o investigación prioritarias. Una 
desventaja fue que representa datos puntuales sobre un solo aspecto de las AV, por lo que es necesaria la aplicación en conjunto para contar con información clara y detallada que permita interrelacionar aspectos sobre estos espacios a fin de tener una visión amplia de las condiciones ambientales en torno a las AV.

En conclusión, los indicadores de AV utilizados evidenciaron diferencias entre las condiciones ambientales en las dos ciudades evaluadas. Además, factibilidad de la aplicación de los indicadores como insumo para la gestión ambiental sostenible de los ecosistemas urbanos.

\section{AGRADECIMIENTOS}

Al Laboratorio PRIAS del Centro Nacional de Alta Tecnología (CeNAT) por el apoyo brindado a través del sistema de becas CONARECeNAT. A Maikol Castillo Chinchilla por la colaboración en la toma de datos en campo. Al Laboratorio de Recursos Naturales y Vida Silvestre (LARNAVISI) de la Escuela de Ciencias Biológicas de la Universidad Nacional. Al proyecto "Criterios e indicadores de sustentabilidad socio-ambiental en dos ciudades de la Gran Área Metropolitana de Costa Rica”.

\section{RESUMEN}

La calidad ambiental contribuye con el bienestar físico y mental de la población. En este sentido las áreas verdes (AV) de las ciudades son espacios esenciales para la convivencia, el deporte, la socialización, y la recreación, entre otros. El objetivo de esta investigación fue determinar las condiciones ambientales de las AV, utilizando indicadores como herramientas para la gestión urbana en dos ciudades de Costa Rica. El área de estudio correspondió a los distritos de Heredia y el Carmen, Costa Rica. Se determinaron las AV existentes utilizando imágenes satelitales Rapid Eye, 2012 mediante análisis espacial y teledetección. Se aplicaron 11 indicadores de áreas verdes urbanas, se identificó la especie, se midió la altura, el DAP y el número de árboles en parques y calles. Además, se realizaron encuestas a los usuarios de las AV públicas, en temas relacionados con accesibilidad y uso de las AV. Se identificaron cinco tipos de AV en el Carmen y seis Heredia. El porcentaje de áreas verdes públicas y privadas correspondió a $36 \%$ y 64 $\%$ en el Carmen y $13 \%$ y $87 \%$ en Heredia, respectivamente. El área verde per cápita $\left(\mathrm{m}^{2} / \mathrm{hab}\right)$ fue de 24.6 en el
Carmen y de 2.7 en Heredia. Se identificaron 62 especies de árboles en los parques del Carmen y 23 en Heredia. Se contabilizaron 1105 árboles de 61 especies en las calles, aceras y avenidas del Carmen y 278 individuos de 47 especies en Heredia. En cuanto a la existencia de vegetación ribereña se determinó que los ríos Pirro, Burrio, Torres y la quebrada Negritos mantienen 82, 51, 81 y $14 \%$ del área de protección de sus márgenes en uso conforme. De $11 \mathrm{AV}$ públicas evaluadas, nueve presentaron una accesibilidad física alta. En ambos distritos los ciudadanos encuestados indicaron la necesidad de contar con más $\mathrm{AV}$, resaltando el valor recreativo, ecológico y turístico de estos espacios. Se concluye que los indicadores de AV urbanas evidenciaron diferencias entre las condiciones ambientales en las dos ciudades evaluadas, y la factibilidad de su aplicación como insumo para la gestión ambiental sostenible de los ecosistemas urbanos.

Palabras clave: indicadores ambientales; áreas verdes urbanas; Costa Rica; ciudades; parques.

\section{REFERENCIAS}

Agencia de ecología urbana de Barcelona. (2010). Plan de Indicadores de Sostenibilidad Urbana de Vitoria-Gasteiz. Recuperado de http://www.vitoria-gasteiz.org/wb021/http/contenidosEstaticos/adjuntos/ es/89/14/38914.pdf

Aguado, M., Calvo, D., Dessal, C., Riechmann, J., González, J., \& Montes, C. (2012). La necesidad de repensar el bienestar humano en un mundo cambiante. Papeles de relaciones ecosociales y cambio global, 119, 49-76.

Alfaro, M. (2016). La amigabilidad de la ciudad de Heredia con los ancianos, medida a partir de sus características físicas. Revista Geográfica de América Central, $57,71-96$.

Amaya, M., Herreño, G., Aparicio, J., Machena, G., Pérez, J., Valverde, M., \& Cortés, I (2008). Plan local de arborización urbana, localidad de Usme. Recuperado de http://oab2.ambientebogota.gov.co/es/documentacion-e-investigaciones/resultado-busqueda/ plan-local-de-arborizacion-urbana-localidad-usme

Argañaraz, J. P. \& Lorenz, G. (2010). Contribución de las áreas verdes urbanas a la regulación del balance de agua en Santiago del Estero, Argentina. Bosque, 31(3), 231-242.

Arribas, M. (2004). Diseño y validación de cuestionarios. Matronas Profesión, 5(17), 23-29.

Artavia, R. \& Valle, D. (2013). Diagnóstico preliminar de avifauna para instaurar el Corredor Biológico Interurbano Río Torres en el cantón San José. Ambientico, 232-233, 56-63.

Barbosa, O., Tratalos, J., Armsworth, P., Davies, R., Fueller, R., \& Pat, J. (2007). Who benefits with access 
from green space? A case study from Sheffield UK. Landscape and Urban Planning, 83, 187-195.

Bolund, P., \& Hunhammar, S. (1999). Ecosystem services in urban areas. Ecological Economics, 29, 293-301.

Breuste, J., Qureshi, S., \& Li, J. (2013). Scaling down the ecosystem services at local level for urban parks of three megacities. Hercynia, 46, 1-20.

Breuste, J., Schnellinger, J., Qureshi, S., \& Faggi, A. (2013). Urban Ecosystem services on the local level: Urban green spaces as providers. Ekológia (Bratislava), 32(3), 290-304. DOI: 10.2478/eko-2013-0026

Cerdas, C. (2014). Evaluación de la arborización en parques urbanos sobre la avifauna en el sureste del cantón central de San José, Costa Rica (Tesis de grado). Universidad Nacional, Costa Rica.

Comisión Nacional de Medio Ambiente (CONAMA). (2002). Áreas verdes en el Gran Santiago (Informe Técnico). Santiago, Chile: Área Ordenamiento Territorial y Recursos Naturales.

Cueva, J. \& Chalán, L. (2010). Cobertura vegetal y uso actual del suelo de la provincia de Loja (Informe Técnico). Ecuador: Departamento de sistemas de información geográfica de la Naturaleza \& Cultura Internacional.

Escobar, G. (2009). Manual de arborización: guia práctica para la selección, siembra, cuidado y protección de árboles y palmas, en zonas blandas y parques de Santiago de Cali. (Informe Técnico). Colombia: Municipalidad de Cali.

Fernández, I. \& González, F. (2008). Plan de acción para los parques y zonas verdes urbanas de Santander: medidas para conservar e incrementar su biodiversidad (Informe Técnico). España: Ayuntamiento de Santander y la Sociedad Española de Ornitología (SEO/BirdLife).

Flores, R. (2012). Incorporando desarrollo sustentable y gobernanza a la gestión y planificación de áreas verdes urbanas. Frontera Norte, 24(48), 165-190.

Gómez, A. (2013). Localización y acceso al verde urbano de la ciudad de Salamanca. Boletín de la Asociación de Geógrafos Españoles, 63, 125-145.

Gómez, F. (2005). Las zonas verdes como factor de calidad de vida en las ciudades. CIUDAD Y TERRITORIO Estudios Territoriales, 37(144), 417-436.

González, C. (2009). Nuevas formas de entender la naturaleza urbana. Áreas verdes en las ciudades. Revista Ambienta, 94, 1-9.

Gurrutxaga, M. \& Lozano, P. (2007). Criterios para contemplar la conectividad del paisaje en la planificación territorial y sectorial. Investigaciones Geográficas, $44,75-88$.
Handley, J., Pauleit, S., Slinn, P., Barber, A., Baker, M., \& Jones, C. (2003). Accessible Natural Green Space Standards in Town and Cities: A Review and Toolkit for their Implementation. Recuperado de http://publications.naturalengland.org.uk/publication/65021

Harvey, C. A., Guindon, C. F., Haber, W. A., Hamilton, D. \& Murray, K. G. (2007). Importancia de los fragmentos de bosque, los árboles dispersos y las cortinas rompe vientos para la biodiversidad local y regional: el caso de Monteverde, Costa Rica. En C. A. Harvey, \& J. Sáenz (Eds.), Evaluación y conservación de la biodiversidad en paisajes fragmentados de Mesoamérica (pp. 289-326). San José, Costa Rica: INBio.

Hernández, A. (2009). Calidad de vida y medio ambiente urbano. Indicadores locales de sostenibilidad y calidad de vida urbana. Revista INVI, 4, 79-111.

Instituto Nacional de Estadística y Censos (INEC). (2011). Censo Nacional de Población y VI de Vivienda 2011. Resultados Generales. 55. Recuperado de http:// www.inec.go.cr/censos/censos-2011

Jiménez, Q. (2013). Arbolado urbano: beneficios, desaciertos y realidad en la Gran Área Metropolitana. Ambientico, 4(12), 232-233.

La Gaceta. (1996). Ley Forestal № 7575. Costa Rica. 16 de abril, 1996.

La Gaceta. (1996). Ley Orgánica del Ambiente $N^{\circ} 7554$. Costa Rica. 4 de octubre, 1995.

Lee, A., \& Maheswaran, R. (2011). The health benefits of urban green spaces: a review of the evidence. Journal of Public Health, 33(2), 212-222.

Lossio, O. (2011). El uso de imágenes satelitales y aerofoto-gráficas en la enseñanza de la geografía. Revista Geográfica de América Central, 47E(2), 1-17.

MacGregor-Fors, I. (2008). Relation between habitat attributes and bird richness in a western Mexico suburb. Landscape and Urban Planning, 84(1), 92-98.

Martínez, M. (2011). Interconexión de las áreas verdes en áreas urbanas. Estudio de caso: urbanización los Cedro de Villa $1^{a}$ etapa-distrito Chorrillos, Lima (Tesis de pregrado). Universidad Católica, Perú.

McDonald, R. (2009). Ecosystem service demand and supply along the urban to rural gradient. Journal of Conservation Planning, 5, 1-14.

Mena, C., Ormazábal, Y., Morales, L., Santelices, R., \& Gajardo, J. (2011). Índices de área verde y cobertura vegetal para la ciudad de Parral (Chile), mediante fotointerpretación y SIG. Ciencia Forestal, Santa María, 21(3), 521-531.

Meza, C. \& Moncada, J. (2010). Las áreas verdes de la ciudad de México: un reto actual. Revista Electrónica de Geografia y Ciencias Sociales, 331(56), 1-10. 
Municipalidad de Heredia. (2009). Plan de desarrollo humano local, cantón central de Heredia, 20102020. Recuperado de https://www.heredia.go.cr/sites/ default/files/plan_de_desarrollo_humano_local_ modificado_a_set2014.pdf

Municipalidad de San José. (2012). Plan de desarrollo municipal 2012-2016. Recuperado de https://www. msj.go.cr/informacion ciudadana/SiteAssets/plan desarrollo_municipal/Plan\%20Desarrollo\%20Muni-

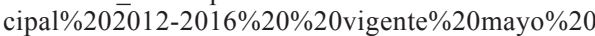
2013.pdf

Observatorio Ambiental. (2017). Indicadores ambientales. Recuperado de http://www.observatorioambiental. una.ac.cr/

Observatorio del Desarrollo. (2017). Filosofia de trabajo. Recuperado de http://www.odd.ucr.ac.cr/

Ortiz, E. (2008). Atlas Digital de Costa Rica 2008. [CD-ROOM.]. Costa Rica: Instituto Tecnológico de Costa Rica.

Piedra-Castro, L., Bermúdez-Rojas, T., \& Romero-Vargas, M. (2013). Costa Rica. En I. Mcgregor-Fors, \& R. Ortega-Álvarez (Eds.), Ecología urbana: experiencias en América Latina (pp. 74-81). Veracruz, México: INECOL. ISBN: 978-607-00-6869-0.

Pinzón, M. \& Echeverri, I. (2010). Espacio público, cultura y calidad ambiental urbana una propuesta metodológica para su intervención. Investigación \& Desarrollo, 18(1), 92-113.

Rente, J., Krishnamurthy, L., \& Juhani, J. (1997). Áreas verdes urbanas en América Latina: una introducción. En L. Krishnamurthy, \& J. Rente-Nascimento (Eds.), Áreas Verdes Urbanas en Latinoamérica y el Caribe (pp. 1-13). Chapingo, México: Universidad Autónoma de Chapingo.

Reyes, S. \& Figueroa, I. (2010). Distribución, superficie y accesibilidad de las áreas verdes en Santiago de Chile. EURE Revista Latinoamericana de Estudios Urbanos Regionales, 36(109), 89-110.

Romano, C. (2005). Formulación de indicadores ecológicos urbanos, relativos a la cobertura vegetal pública y su aplicación en la localidad de Usaquén (Bogotá, Colombia) (Tesis de grado). Universidad Javeriana, Colombia.

Sánchez, G. \& Artavia, R. (2013). Inventario de la foresta en San José: Gestión Ambiental Urbana. Ambientico, 232-233, 26-33.

Segura, R. \& Trincado, G. (2003). Cartografía digital de la Reserva Nacional Valdivia a partir de imágenes satelitales Landsat TM. Bosque (Valdivia), 24(2), 43-52.

Subirats, J., Quintana, I., Vidal, M., \& Rueda, S. (2012). Capitulo XI. El libro verde de la sostenibilidad urbana y local en el ámbito de la sostenibilidad social: hábitat urbano e inclusión social. En Rueda, S. (Ed.), Libro verde de sostenibilidad urbana y local en la era de la información (pp. 453-495). España: Ministerio de Agricultura, Alimentación y Medio Ambiente.

Sugiyama, T., \& Ward-Thompson, C. (2008). Associations between characteristics of neighbourhood open space and older people's walking. Urban Forestry \& Urban Greening, 7, 41-51.

Vargas-Garzón, B. \& Molina-Prieto, L. F. (2010). Cinco árboles urbanos que causan daños severos en las ciudades. Revista Nodo, 9(5), 115-126. 